EESTI NSV TEADUSTE AKADEEMIA TOIMETISED. XVII KOIDE

KEEMIA * GEOLOOGIA. 1968, Nr. 4

ИЗВЕСТИЯ АКАДЕМИИ НАУК ЭСТОНСКОИ ССР. ТОМ ХVII

Химия - ГЕОЛогия. 1968, ㅃ 4

К. ЛЭЭТС

\title{
СИНТЕЗ ТЕРПЕНОВЫХ ПРОИЗВОДНЫХ ИЗ ИЗОПРЕНА МЕТОДОМ ТЕЛОМЕРИЗАЦИИ
}

Терпеновые окси- и оксопроизводные алифатического строения, такие, как цитраль, псевдоионон, гераниол, линалоол, являются незаменимыми исходными веществами для получения многих ценных синтетических душистых веществ, а также витаминов $\mathrm{A}, \mathrm{E}$ и $\mathrm{K}$.

Еще два десятилетия назад указанные вещества производились исключительно из природных эфирных масел. Ввиду дефицитности и дороговизны натурального сырья в производстве терпеновых производных все большее значение приобретают синтетические методы их получения.

Известно, что основу химической структуры молекулы терпенов составляет молекула изопрена - 2-метилбутадиена-1,3.

До настоящего времени в производстве синтетических терпенов наи более широко применялись способы синтеза терпенов на основе ацетона и ацетилена, а также синтезы из более доступных природных терпенов, выделяемых из скипидара - $\alpha$ - и $\beta$-пиненов. Причиной этого являлась бо́льшая доступность сырья и наличие хорошо разработанных химических способов осуществления указанных синтезов.

Прямые синтезы терпеновых производных из изопрена пока еще не нашли широкого промышленного применения, хотя уже в 1932 году работами Вагнера-Яурегга ['] была показана возможность получения терпеновых и сесквитерпеновых оксипроизводных алифатического строения при взаимодействии изопрена с уксусной кислотой в присутствии серной кислоты. Әту реакцию можно рассматривать как реакцию полимеризации изопрена с одновременным присоединением элементов уксусной кислоты. Позднее реакции подобного типа получили общее название реакции теломеризации, которую схематически можно изобразить в виде

$$
\underset{\text { телоген }}{n \mathrm{RX}}+m \mathrm{~A} \underset{\text { мономер }}{\longrightarrow} \mathrm{RAX}+\underset{\text { теломер }}{\mathrm{RA}_{2} \mathrm{X}}+\ldots+\mathrm{RA}_{z} \mathrm{X}
$$

Подробные исследования, проведенные в последнее время в нашей лаборатории $\left[{ }^{2}\right]$, показали, что при этой реакции образуется смесь углеводородов и ацетатов изомерных терпеновых спиртов в результате присоединения радикала 3-метил-бутен-2-ила- $\left(\mathrm{CH}_{3}\right)_{2} \mathrm{C}=\mathrm{CH}-\mathrm{CH}_{2}^{+}$к изөпрену в положениях 1,3 и 4 , а также циклизации образуемых өксипроизводных аллильного строения.

Фракция монотерпеновых ацетатов, образующаяся в результате реакции, содержит в основном следующие изомеры: 


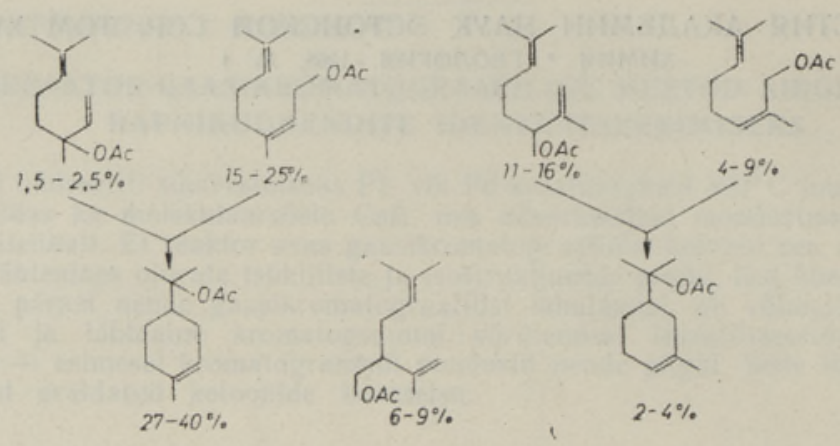

Кроме того, во фракции присутствуют еще десять изомеров неизвестного строения в суммарном количестве $10-20 \%$.

Разделение получаемых смесей изомерных ацетатов и углеводородов представляет сложную задачу и экономически вряд ли целесообразно, хотя упомянутая реакция представляет несомненный интерес для осуществления прямого синтеза терпеновых оксипроизводных из изопрена.

Вторая схема получения терпеновых производных из изопрена методом теломеризации была предложена автором настоящего сообщения в 1955 году [3]. При этом в качестве телогена использовалась смесь моногидрохлоридов изопрена, образующаяся при гидрохлорировании изопрена с газообразным хлористым водородом по схеме

$$
\mathrm{CH}_{2}=\mathrm{C}\left(\mathrm{CH}_{3}\right)-\mathrm{CH}=\mathrm{CH}_{2}+\mathrm{HCl} \underbrace{\left(\mathrm{CH}_{3}\right)_{2} \mathrm{CCl}-\mathrm{CH}=\mathrm{CH}_{2}}_{\left(\mathrm{CH}_{3}\right)_{2} \mathrm{C}=\mathrm{CH}-\mathrm{CH}_{2} \mathrm{Cl}}
$$

В качестве катализаторов применялись кислоты Льюиса. Схематически предложенную реакцию можно представить в следующем виде:

$$
n \mathrm{C}_{5} \mathrm{H}_{9} \mathrm{Cl}+m \mathrm{C}_{5} \mathrm{H}_{8} \rightarrow \mathrm{C}_{10} \mathrm{H}_{17} \mathrm{Cl}+\mathrm{C}_{15} \mathrm{H}_{25} \mathrm{Cl}+\ldots+\mathrm{C}_{5} \mathrm{H}_{9}\left(\mathrm{C}_{5} \mathrm{H}_{8}\right)_{n} \mathrm{Cl}
$$

Дальнейшими исследованиями было показано [4], что изученная реакция теломеризации проходит с образованием из исходных гидрохлоридов изопрена радикала 3-метил-бутен-2-ила, который присоединяется к изопрену преимущественно в положении 1 .

Одновременно протекают также реакции циклизации образующихся галогенопроизводных аллильного строения $(20 \%)$ и димеризации исходных гидрохлоридов изопрена $(10 \%)$.

Соответствующий подбор катализатюра $\left(\mathrm{SnCl}_{4}\right)$ и условий реакции [3.5] позволил получить продукт с преимущественным содержанием геранилхлорида и фарнезилхлорида (продукты 1,4-присоединения).

При использовании в качестве катализатора безводного хлорного олова в реакционной смеси присутствуют еще продукты присоединения в положениях $3,4 \sim 5 \%\left[{ }^{4}\right]$ и в положениях $4,3 \sim 8 \%\left[{ }^{6}\right]$.

Получаемая фракция монотерпеновых галогенопроизводных содержит изомеры, указанные в начале стр. 357.

Разделение получаемой смеси синтетических хлорпроизводных терпенов, как и в случае продукта Вагнер-Яурегга, обычными физикохимическими методами является сложной задачей.

Однако благодаря различной реакционной способности атомов галогена в молекулах изомерных терпеновых галогенопроизводных удалось разработать ряд селективных химических способов выделения из 

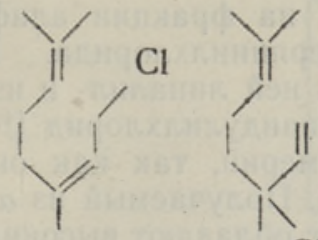

$\mathrm{Cl}$

линалилхлорнд
$5-10 \%$ хлорид $50-65 \%$

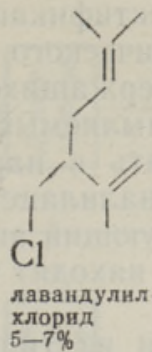

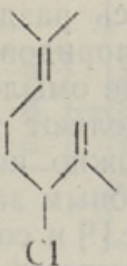

3-Cl-2,7-диметнл октаднен-1,6 (изолиналилхлорид) $7-10 \%$

$\boldsymbol{\alpha}$-терпкнилхлорид $12-18 \%$

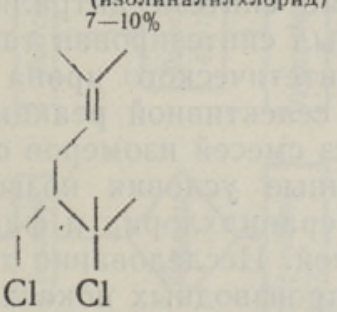

2-C1-2.6-диметил-3-Cl-метнл-гептен-5-(димер гидрохлорндов изопрена) 5-10\%

технической смеси индивидуальных соединений и превращения их в соответствующие терпеновые окси- и оксопроизводные высокой чистоты.

Проведенный комплекс исследований позволил разработать схему, которую можно поставить в один ряд с другими методами синтеза терпеновых производных, представляющих практический интерес.

Разработанные нами способы переработки продукта теломеризации в индивидуальные терпеновые производные базируются на селективном взаимодействии галогенопроизводных с органическими основаниями, содержащими третичный атом азота, а также на реакциях фракционированного омыления.

Первой селективной реакцией, применение которой позволило осуществить синтез терпеновых оксопроизводных по указанной схеме, была реакция первичных хлоридов аллильного типа с уротропином. С помощью этой реакции из фракции изомерных терпеновых хлоридов удалось выделить практически количественно геранилхлорид [ $\left.{ }^{4}\right]$. Используя реакцию Соммле, полученное соединение с хорошим выходом былэ переведено в цитраль [7] по схеме

$$
\begin{aligned}
& y=\left\lfloor-\mathrm{Cl}+\mathrm{C}_{6} \mathrm{H}_{12} \mathrm{~N}_{4} \rightarrow\right. \\
& \text { геранилхлорид уротропин } \\
& \left.\left\lceil=\searrow=-\mathrm{N}_{4} \mathrm{C}_{6} \mathrm{H}_{12}\right]^{+} \mathrm{Cl}-\frac{\mathrm{H}_{2} \mathrm{O}}{100^{\circ} ; \mathrm{CH}_{2} \mathrm{O}}\right\rangle=\searrow_{\mathrm{CHO}}
\end{aligned}
$$

Получаемый продукт обладает высокой чистотой $(98 \%)$, хорошими парфюмерными качествами и содержит около $20 \%$ нераля и $80 \%$ гераниаля $\left[{ }^{8}\right]$.

Из синтезированного цитраля были получены $\psi$-ионон, а также $\boldsymbol{\beta}$-ионон - исходное вещество для производства синтетического витамина A [8].

С целью использования оставшихся после выделения геранилхлорида изомерных терпеновых хлорпроизводных были разработаны методы получения из них индивидуальных терпеновых спиртов и их производных, имеющих практическое значение [ $\left.{ }^{4}\right]$. Изомерные хлорпроиз- 
водные удалось разделить ректификацией на фракции алифатических терпеновых хлоридов и циклического $\alpha$-терпинилхлорида. Из первой фракции, после омыления содержащихся в ней линалил- и изолиналилхлоридов, отделяют трудноомыляемый лавандулилхлорид [4,6]. Ацетат последнего можно использовать в парфюмерии, так как он обладает запахом, подобным запаху линалилацетата. Получаемый из $\alpha$-терпинилхлорида спирт $\left[{ }^{4}\right]$ и соответствующий ацетат обладают высокими парфюмерными качествами и также находят применение в парфюмерных композициях.

По схеме синтеза цитраля из гидрохлоридов диметилбутадиена и изопрена был синтезирован также метилцитраль, используемый для получения синтетического ирона [ $\left.{ }^{9}\right]$.

Второй селективной реакцией для выделения первичных аллильных хлоридов из смесей изомеров оказалась реакция с диметиланилином [10․ Разработанные условия позволили селективно выделить из фракций $\mathrm{C}_{10}$ и $\mathrm{C}_{15}$ геранилхлорид и фарнезилхлорид в виде четвертичных аммониевых солей. Исследование термического разложения получаемых аммониевых производных показало, что при повышенной температуре они превращаются без изомеризации в исходные галогенопроизводные и амин $\left[{ }^{10,11}\right]$. Установлено также, что омыление выделенных первичных галогенопроизводных происходит с полной аллильной перегруппировкой, в результате которой получаются душистые вещества линалоол и неролидол.

Были также найдены способы алкилирования выделенными аммониевыми солями органических кислот [12] и ацетоуксусного и малонового эфиров [13]. В результате были получены душистые вещества гераниол и фарнезол, а также геранилацетон, фарнезилацетон и геранилуксусная кислота. Все эти вещества являются полупродуктами для получения терпеновых производных более сложного строения. Из синтезированного фарнезилацетона получен гидрированием $6,10,14$-пентадеканон-2, через который можно осуществить переход к фитолу и дальше к $\boldsymbol{\alpha}$-токоферолу и филлохинону - синтетическим витаминам Е и $\mathrm{K}$.

В результате проведенных исследований предложена комплексная схема синтеза терпеновых производных из изопрена.

В настоящее время разработанные синтезы осуществлены в опытнопромышленных условиях или внедряются в производство.

В итоге необходимо отметить, что разработанная схема прямого синтеза терпеновых производных из изопрена в экономическом отношении уже сейчас успешно конкурирует с другими известными схемами производства аналогичных продуктов из химического сырья. Особо следует указать на возможность получения наряду с монотерпеновыми производными сесквитерпеновых производных, синтез которых по уже известным схемам отличается значительной сложностью.

В связи с быстрыми темпами развития мирового производства изопрена для выработки синтетического каучука прямые синтезы терпеновых производных из изопрена приобретают все более широкую перспективу и в ближайшее время могут составить основу производства большинства синтетических душистых веществ терпеноидного строения.

\section{Выводы}

Приведен обзор исследований, посвященных разработке нового направления синтеза терпеновых производных из изопрена методом теломеризации. На основе результатов исследований предложена комплексная схема производства полупродуктов для получения синтетических витаминов A, E, K, душистых веществ и биопрепаратов. 


\section{Л И ТЕ РА Т У Р А}

1. Wägner-J a uregg Th., Ann. 496, 52 (1932).

2. Э р м А., Л э эт с К., Изв. АН ЭССР, Хим. Геол., 16, № 1, 37 (1967).

Л ээ тс. К., Эрм А., Ли п п а а Э., Пускар Ю., Изв. АН ЭССР, Хим.

Геол., 17, № 4 (1968).

3. Л ээт с К., Авт. свид. № 105428, 1955; ЖОХ, 58, 1823 (1958).

4. Л ээтс К., ЖОХ, 28, 3096 (1958).

5. Петров А. и др., ЖОХ, 28, 1435 (1958).

6. Л ээтс К., К а ал Т., Юрьен с Х., Изв. АН ЭССР, Хим. Геол., 17, № 4 (1968),

7. Лээтс К. и др., ЖОХ, 27, 1510 (1957).

8. Кудря вцев И., Т али М., Лээтс К., Изв. АН ЭССР, Хим. Геол., 17, № 4 (1968).

9. Бе лов В. и др., ЖОХ, 27, 1384 (1957).

10. Л э э т с К., Авт. свид. № 128860, 1959; ЖОХ, 31, 1869 (1961).

11. Лээт с К., Тенг С., Изв. АН ЭССР, Хим. Геол., 16, № 4, 292 (1967).

12. Лээ тс К., Авт. свид. № 130042, 1959; Лээтс К., Когерман А., Изв. АН ЭССР, Хим. Геол., 17, № 4 (1968).

13. Л ээт с К., Когерм ан А., Авт. свид. № 184267, 1962; Бюлл. изобр., № 15, 1966.

Институт химии

Академии наук Эстонской ССР

Поступила в редакцию 22/IV 1968

\section{K. LAATS}

\section{TERPEENDERIVAATIDE SUNTEES ISOPREENIST TELOMERISATSIOONIMEETODIL}

Olevaade uuest terpeenderivaatide sünteesimeetodist isopreeni telomerisatsiooni reaktsionnil. Seniste uurimiste alusel esitatakse isopreenist sünteetilise A-, E- ja K-vitamiini, löhnaainete ja biopreparaatide lähteainete tootmise kompleksne skeem.

\section{K. LAATS}

\section{SYNTHESIS OF TERPENE DERIVATIVES FROM ISOPRENE BY THE TELOMERIZATION METHOD}

A review is given of a new method of synthesizing terpene derivatives by means of an isoprene telomerization reaction. On the basis of the investigations effected, a complex scheme is suggested for the production, from isoprene, of synthetic vitamins $\mathrm{A}, \mathrm{E}, \mathrm{K}$, as well as perfumery substances and biopreparations. 